\title{
Estudo Clínico-Epidemiológico da Infeção Complicada por Vírus Varicela-Zoster na Idade Pediátrica
}

\author{
Clinical and Epidemiological Study of Complicated Infection by Varicella-Zoster \\ Virus in the Pediatric Age
}

Catarina MAIA $\triangle^{1}$, Jacinta FONSECA ${ }^{1}$, Isabel CARVALHO $^{1}$, Helena SANTOS ${ }^{1}$, Diana MOREIRA ${ }^{1}$

Acta Med Port 2015 Nov-Dec;28(6):741-748

RESUMO

Introdução: Em Portugal, a incidência da infeção complicada por vírus varicela-zoster e respetivos custos é desconhecida. O objetivo deste estudo foi descrever as características clinico-epidemiológicas dos doentes em idade pediátrica internados com o diagnóstico de infeção complicada por vírus varicela-zoster.

Material e Métodos: Estudo descritivo, baseado na análise dos processos clínicos dos doentes internados entre janeiro de 1999 e julho de 2013, com diagnóstico de infeção complicada por vírus varicela-zoster.

Resultados: Foram internados 94 doentes por infeção complicada a vírus varicela-zoster, dois por reativação de infeção latente. A mediana da idade foi 38 (IQR 18 - 65) meses. As complicações mais frequentes foram as infeciosas $(70,2 \%)$, destacando-se a sobreinfeção bacteriana da pele/tecido celular subcutâneo $(37,2 \%)$ e as complicações respiratórias $(24,5 \%)$. Seguiram-se as complicações neurológicas $(19,1 \%)$, gastrointestinais $(9,6 \%)$, hematológicas $(5,3 \%)$ e osteoarticulares $(4,3 \%)$. Diagnosticaram-se $38(40,4 \%)$ infeções bacterianas invasivas, seis com bacteriemia. A mediana da idade na admissão foi mais elevada nas complicações imunológicas relativamente às complicações infeciosas. As complicações neurológicas ocorreram preferencialmente em crianças saudáveis, enquanto as complicações infeciosas, nomeadamente as infeções bacterianas invasivas foram mais frequentes nos doentes medicados com ibuprofeno e/ou corticoide. A evolução foi favorável na maioria dos casos.

Discussão: As complicações da infeção pelo vírus varicela-zoster ocorreram preferencialmente em idade pré-escolar e doentes saudáveis. As complicações infeciosas, nomeadamente as dermatológicas e respiratórias, foram as mais frequentes, tendo sido verificada associação com a terapêutica prévia com ibuprofeno e lou corticoide.

Conclusão: Estudos multicêntricos deverão ser planeados com o intuito de otimizar e ajustar as estratégias vacinais à nossa realidade.

Palavras-chave: Criança; Criança Hospitalizada; Herpes Zoster; Herpesvirus Humano 3; Portugal; Varicela.

\section{ABSTRACT}

Introduction: In Portugal, the incidence of complicated infection by varicella-zoster virus is unknown. The purpose of this study was to describe the epidemiological and clinical features of complicated infection by varicella-zoster virus in children.

Material and Methods: Retrospective review of the clinical files of patients admitted between January 1999 and July 2013 , with a diagnosis of complicated varicella-zoster virus infection.

Results: Ninety-four patients were hospitalized with complicated varicella-zoster virus infection, two of them by reactivation of latent infection. The median age was 38 (IQR 18 - 65) months. The most frequent types of complications were bacterial overinfection of the skin and subcutaneous cellular tissue (37.2\%) and respiratory complications $(24.5 \%)$. Other complications were neurologic complications $(19.1 \%)$, gastrointestinal $(9.6 \%)$, hematologic $(5.3 \%)$ and osteoarticular $(4.3 \%)$. In 38 patients invasive bacterial infections were diagnosed, with bacteremia in 6 patients. The median age was highest in the immunological complications compared with infectious complications. Neurological complications occurred mainly in healthy children, while infectious complications, including the invasive bacterial infections were more frequent in patients treated with ibuprofen and/or corticosteroids. The evolution was favorable in most cases.

Discussion: The complications of varicella-zoster virus infection occurred mainly in pre-school age and in healthy children. Infectious complications, particularly respiratory complications and bacterial overinfection of the skin and subcutaneous cellular tissue, were the most frequent. There was association between infectious complications and previous therapy with ibuprofen and / or corticosteroids.

Conclusion: Multicenter studies should be planned in order to optimize and adjust the vaccine strategies to our reality.

Keywords: Chickenpox; Child; Child, Hospitalized; Herpesvirus 3, Human; Herpes Zoster; Portugal.

\section{INTRODUÇÃO}

$\mathrm{O}$ virus varicela-zoster $(\mathrm{VVZ})$ é um virus pertencente à família Herpesviridae e é o agente causal da varicela e do herpes zoster. A varicela é uma doença frequente na infância e altamente contagiosa, afetando principalmente crianças menores de 12 anos. Ao longo do tempo tem-se assistido a um aumento da incidência da varicela nas crianças ${ }^{1}$ com cerca de $95 \%$ dos adultos imunes na faixa etária dos 20 - 29 anos. $^{2}$ Geralmente apresenta uma evolução auto-limitada e benigna, contudo pode associar-se a complicações e a necessidade de internamento em cerca de $2-6 \%$ dos casos. ${ }^{3-5}$

A complicação mais frequentemente descrita é a sobreinfeção bacteriana da pele e tecidos moles, cujos agentes mais envolvidos são o Staphylococcus aureus e o Streptococcus pyogenes. Seguem-se as complicações neurológicas e as complicações respiratórias.

1. Serviço de Pediatria Médica. Centro Hospitalar Vila Nova de Gaia/Espinho. Gaia. Portugal.

$\triangle$ Autor correspondente: Catarina Maia. catarinammaia@gmail.com

Recebido: 31 de Janeiro de 2015 - Aceite: 30 de Junho de 2015 | Copyright @ Ordem dos Médicos 2015 
Menos frequentes são as complicações hematológicas, as complicações gastrointestinais e as complicações osteoarticulares. ${ }^{6}$ Após a infeção primária, o VVZ fica em latência nos gânglios nervosos, podendo reativar sob a forma de herpes zoster e evoluir com complicações semelhantes à varicela. Esta reativação é pouco frequente em idade pediátrica, nomeadamente em crianças imunocompetentes, estando mais frequentemente descrito em latentes que foram infetados in utero ou durante o primeiro ano de vida. ${ }^{6}$

Em Portugal, a infeção pelo VVZ não é uma doença de declaração obrigatória. De acordo com os resultados apresentados pela rede de Médicos Sentinela foram notificados, durante o ano de 2009, 310 casos de varicela. ${ }^{7}$ As taxas de incidência estimadas foram de 414,6 casos por 100 000 utentes por ano na população geral, sendo de 5 194,1 por 100000 utentes/ano no grupo etário dos 0 - 4 anos e de 2131,5 por 100000 utentes/ano no grupo etário dos 5 - 9 anos. $^{7}$ O Segundo Inquérito Serológico Nacional (Portugal Continental), que decorreu entre 2001 e 2002 mostrou que $41,3 \%$ das crianças entre os 2 e 3 anos apresentam anticorpos IgG para o VVZ, valor que aumenta para $83,6 \%$ aos $6-7$ anos e $94,2 \%$ entre os 15 e 19 anos. ${ }^{8}$

A vacina contra o VVZ foi introduzida no nosso país em outubro de 2004 , sendo de prescrição individual e recomendada em adolescentes (11 - 13 anos) e grupos de risco, nomeadamente em indivíduos não imunes em ocupações de alto risco, mulheres não imunes previamente à gravidez, pais de criança jovem não imunizados e adultos ou crianças que contactam habitualmente com doentes imunodeprimidos. $^{9}$

Relativamente às hospitalizações, complicações, mortalidade e custos relacionados com o VVZ, os estudos em Portugal são, ainda, escassos..$^{10}$

Os objetivos deste estudo foram: caracterizar clínica e epidemiológicamente os doentes em idade pediátrica internados com o diagnóstico de infeção complicada por VVZ, assim como identificar os fatores preditivos dos diferentes tipos de complicações.

\section{MATERIAL E MÉTODOS}

\section{Desenho do estudo e amostra populacional}

Estudo descritivo, do tipo estudo de casos, dos doentes internados num hospital urbano do norte de Portugal, entre janeiro de 1999 e julho de 2013. Neste estudo foram incluídos todos os doentes em idade pediátrica (inferior a 18 anos) internados com o diagnóstico de infeção por VVZ (varicela ou herpes zoster). Foram excluídos os doentes internados com infeção por VVZ não complicada e aqueles cujas lesões de varicela apareceram durante a permanência no hospital (Fig. 1).

\section{Protocolo do estudo}

Análise dos processos clínicos dos doentes internados com diagnóstico de infeção complicada por VVZ entre janeiro de 1999 e julho de 2013. O diagnóstico de infeção por VVZ baseou-se nos sintomas e sinais clínicos.

Definiu-se varicela como exantema polimorfo pruri- ginoso, com lesões em diferentes fases de evolução (inicialmente aspeto maculopapular, de distribuição centrípeta, que, após algumas horas, adquire aspeto vesicular, evoluindo rapidamente para pústulas e, posteriormente, formando crostas), sem outra causa aparente. $O$ herpes zoster foi definido como exantema vesicular localizado, que usualmente envolve a distribuição do dérmatomo de um ou mais nervos sensoriais. ${ }^{11}$

As complicações da infeção por VVZ foram agrupadas segundo a classificação por órgãos/sistemas e segundo a classificação fisiopatológica. Em relação à classificação por sistemas foram divididos em seis grupos: cutâneas/ tecidos moles; neurológicas; respiratórias; gastrointestinais; hematológicas e osteoarticulares. Segundo a classificação fisiopatológica foram agrupadas em três grupos: infeciosas, imunológicas e outras não classificáveis. Entre as complicações infeciosas foram consideradas infeções bacterianas invasivas (IBI): celulite, abcesso, mastoidite, pneumonia, artrite séptica, osteomielite, bacteriemia, sindrome de choque tóxico e sépsis. Consideraram-se complicações imunológicas pós infeção por VVZ as seguintes: ataxia cerebelosa pós-varicela, acidente vascular cerebral (AVC), mielite transversa, parésia de nervo craniano, trombocitopenia imune e artrite reativa. Foram agrupados no grupo de complicações não classificáveis os casos de intolerância oral e as crises febris em contexto apenas de infeção por VVZ.

Foram considerados fatores de risco para varicela complicada, independentemente da idade, a depressão imunológica, as doenças pulmonares, cutâneas ou outras doenças crónicas, a gravidez e a terapêutica prévia com ibuprofeno ou corticoide. ${ }^{12}$

\section{Variáveis demográficas, clínicas e analíticas analisadas}

Idade, sexo, padrão sazonal, fonte de contágio, fatores de risco para varicela complicada, mediana do intervalo de tempo decorrido entre o início da varicela e a complicação, tipo de complicação, tratamento efectuado e tempo de internamento.

\section{Análise Estatística}

Nas comparações entre os grupos, baseadas em variáveis categóricas, foi usado o teste qui-quadrado de independência. Nos casos em que não se verificaram as condições de aplicabilidade do teste qui-quadrado usaram-se os resultados do teste exato. Nas comparações entre os dois grupos baseados em variáveis contínuas recorreu-se ao teste $t$ para amostras independentes ou ao teste não paramétrico de Wilcoxon-Mann-Whitney quando as amostras eram de dimensão reduzida. Para a análise estatística utilizou-se o programa informático SPSS version 20. Considerou-se uma probabilidade de erro tipo I ( $\alpha$ ) de 0,05 em todas as análises inferenciais.

O projeto de investigação deste estudo foi previamente aprovado pela Comissão de Ética da instituição em que a investigação foi realizada, de acordo com a Declaração de Helsínquia da Associação Médica Mundial e do 
International Committee of Medical Journal Editors (ICMJE).

\section{RESULTADOS}

\section{Descrição da amostra populacional}

Durante o período de estudo foram internados 111 doentes com diagnóstico de infeção por VVZ. Destes, foram excluídos 17 por ausência de complicação: sete por risco de varicela complicada (seis por varicela em recém-nascido e um por varicela em doente imunocomprometido), nove por varicela com aparecimento durante a hospitalização e um por intoxicação medicamentosa por paracetamol em criança com varicela.

Dos 94 doentes incluídos no estudo com o diagnóstico de infeção complicada por VVZ, dois $(2,1 \%)$ foram no contexto de reativação de infeção latente (Fig. 1). A mediana da idade foi 38 (IQR 18 - 65) meses, apresentando 80,9\% dos doentes idade inferior a seis anos e $6,4 \%$ idade superior a nove anos. Aproximadamente $50 \%$ da amostra era do sexo masculino. Nenhum dos doentes se encontrava vaci- nado contra o VVZ. Em 27 (28,7\%) doentes foi identificada condição predisponente para varicela complicada: dermatite atópica $(n=5)$, doença pulmonar crónica $(n=9)$, outras doenças crónicas $(n=7)$ e terapêutica prévia com anti-inflamatório não esteróide (AINE) e/ou corticoide ( $n=14$ ). Destes 14 doentes, dez realizaram terapêutica com AINE, mais concretamente ibuprofeno, na fase inicial da doença. Nenhum caso apresentava imunodeficiência primária. A fonte de contágio provável foi identificada em $27(28,7 \%)$ doentes e correspondia maioritariamente a crianças com idade inferior a 10 anos (84,2\%). Dos casos identificados, $20(74 \%)$ foram em contexto intrafamiliar e sete $(26 \%)$ em contexto escolar.

De acordo com a classificação em órgãos/sistemas, as complicações mais frequentes foram a sobreinfecção bacteriana da pele/tecido celular subcutâneo $(37,2 \%)$, seguindo-se as complicações respiratórias $(24,5 \%)$, as complicações neurológicas (19,1\%), as complicações gastrointestinais $(9,6 \%)$, as complicações hematológicas $(5,3 \%)$

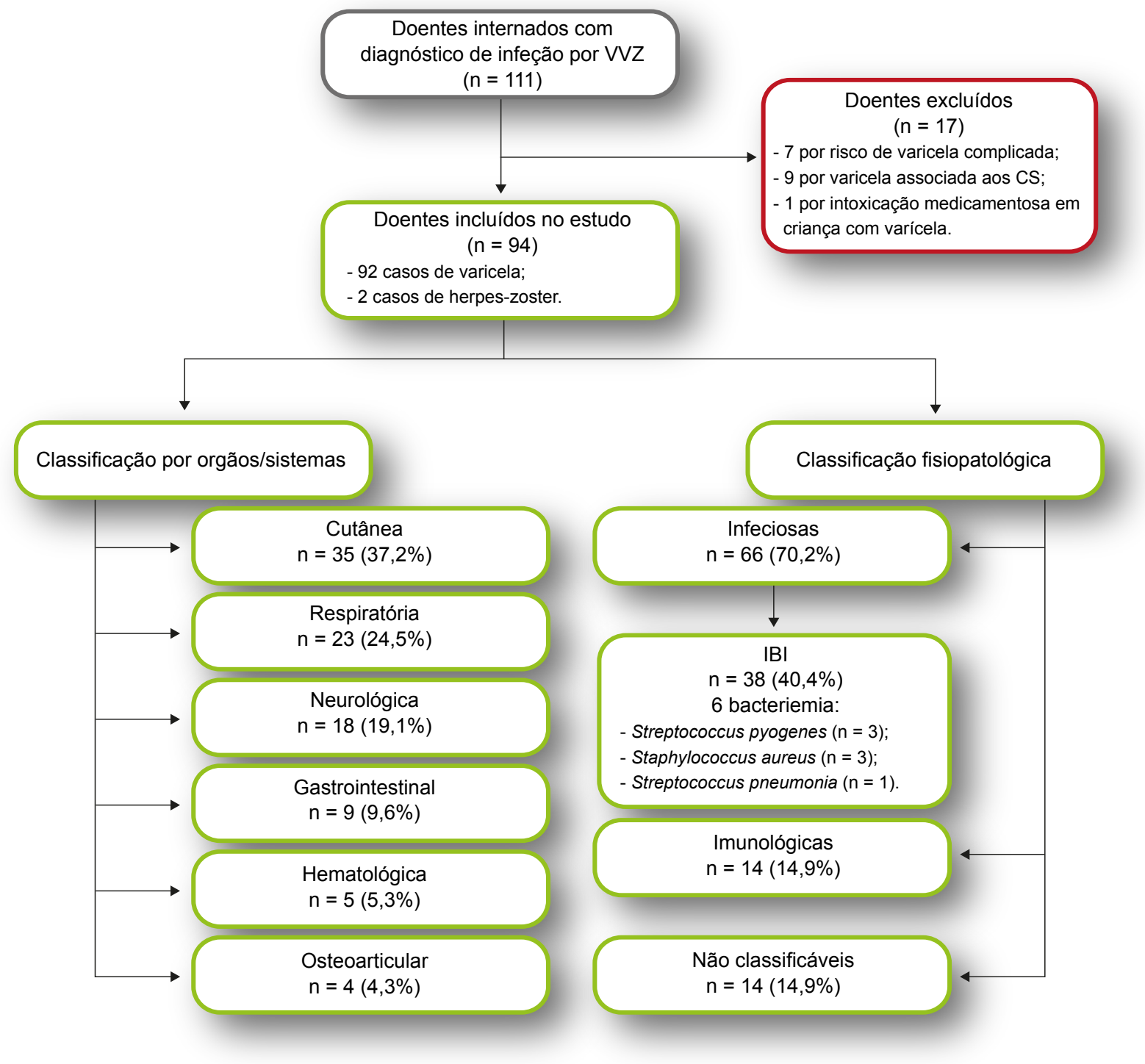

Figura 1 - Fluxograma do estudo

VVZ: Vírus varicela zoster; IBI: Infeção bacteriana invasiva; CS: Cuidados de saúde; GI: Gastrointestinal. 
e as complicações osteoarticulares (4,3\%) (Tabela 1). Não se diagnosticou nenhum caso de fasceíte necrotizante. Em relação à classificação fisiopatológica verificaram-se 66 casos de complicações infeciosas e 14 casos de complicações imunológicas. A co-infeção bacteriana foi confirmada em seis doentes, sendo provável em 53 casos. Diagnosticaram-se $38(40,4 \%)$ IBI, seis das quais com bacteriemia: Streptococcus pyogenes $(n=2)$, Staphylococcus aureus $(n=2)$, Streptococcus pneumoniae $(n=1)$ e co-infeção por

Tabela 1 - Grupo de complicações por sistemas na infeção por VVZ

\begin{tabular}{|c|c|}
\hline \multicolumn{2}{|l|}{ Tipo de Complicações } \\
\hline $\begin{array}{l}\text { Sobreinfeção bacteriana da pele/ } \\
\text { tecidos moles }\end{array}$ & $37,2 \%$ \\
\hline Impetigo & 24 \\
\hline Celulite & 15 \\
\hline Abcesso & 4 \\
\hline Síndrome de choque tóxico & 3 \\
\hline Miosite & 1 \\
\hline Respiratórias & $24,5 \%$ \\
\hline Infecção das vias aéreas superiores & $\begin{array}{c}15 \\
(11 \mathrm{OMA})\end{array}$ \\
\hline Pneumonia & $\begin{array}{c}13 \\
\text { ( } 3 \text { complicadas) }\end{array}$ \\
\hline Otomastoidite & 1 \\
\hline Outras (bronquiolite/sibilância recorrente) & 5 \\
\hline Neurológicas & $19,1 \%$ \\
\hline Ataxia & 5 \\
\hline Meningite & 6 \\
\hline AVC & 1 \\
\hline Mielite & 1 \\
\hline Parésia do sexto nervo craniano & 1 \\
\hline Crises febris & 8 \\
\hline Gastrointestinais & $9,6 \%$ \\
\hline Vómitos & 9 \\
\hline Diarreia & 4 \\
\hline Hepatite & 1 \\
\hline Hematológicas & $5,3 \%$ \\
\hline Trombocitopenia imune & 5 \\
\hline Coagulação intravascular disseminada & 2 \\
\hline Osteoarticulares & $4,3 \%$ \\
\hline Artrite séptica & 2 \\
\hline Artrite reativa & 1 \\
\hline Osteomielite & 1 \\
\hline Total & 94 \\
\hline
\end{tabular}

Streptococcus pyogenes e Staphylococcus aureus $(n=1)$. A co-infeção vírica foi confirmada em três doentes (três enterovirus).

Constatou-se uma tendência de aumento do número de casos ao longo do tempo (5,12 casos/ano entre 1999 e 2006 e 8,05 casos/ano entre 2007 e 2013), com o maior pico durante o período de estudo registado em 2012 (Fig. 2).

A mediana do intervalo de tempo decorrido entre o início da varicela e a complicação foi de 4,0 (IQR:3,0 - 5,0) dias e a mediana de duração do internamento foi de 5,0 (IQR: 3,0 - 8,3) dias.

Trinta e seis doentes $(38,9 \%)$ realizaram terapêutica com aciclovir, sendo que em 18 doentes esta terapêutica foi iniciada por via oral na fase inicial da doença e previamente ao internamento ( 15 nas primeiras 48 horas de doença e, destes, 13 nas primeiras 24 horas). Dezoito doentes iniciaram aciclovir apenas durante o internamento e por via endovenosa. A mediana de duração do tratamento com aciclovir foi cinco dias. $O$ tratamento com aciclovir na fase inicial da doença não se relacionou com a gravidade ou tipo de complicação.

A terapêutica antibiótica foi realizada em 62 casos $(66,0 \%)$, sendo que destes, 44 doentes $(71,0 \%)$ o fizeram em monoterapia. Os principais esquemas terapêuticos utilizados foram: flucloxacilina $(n=14)$, cefuroxima $(n=24)$, associação de flucloxacilina com clindamicina $(n=4)$, associação de cefuroxima com clindamicina $(n=4)$ e ceftriaxone $(n=4)$. Cinco casos necessitaram de tratamento cirúrgico: drenagem de abcesso ósseo em criança com osteomielite do cúbito $(n=1)$; drenagem de abcesso dos tecidos moles $(n=1)$; artrocentese $(n=1)$ e artrotomia $(n=1)$ em doentes com atrite séptica e descortição pleural em criança com empiema e abcesso pulmonar $(n=1)$. A evolução foi favorável na maioria dos casos, no entanto verificaram-se cinco casos com sequelas (duas osteoarticulares, uma neurológica, uma hematológica e uma respiratória), dois deles com repercussões funcionais graves (uma osteoarticular e uma respiratória). Uma das crianças necessitou de internamento na Unidade de Cuidados Intensivos Pediátricos. Não se verificou nenhum caso de mortalidade.

\section{Comparação entre os grupos de complicações}

A mediana da idade na admissão foi significativamente mais elevada nas complicações imunológicas em comparação com as complicações infeciosas ( 64,0 vs 30,0 meses; $p=0,001$ ). Os doentes com complicação imunológica eram predominantemente do sexo feminino (Tabela 2).

A mediana do intervalo de tempo decorrido entre o início da varicela e a complicação foi significativamente mais elevada nas complicações imunológicas $(p=0,001)$.

As complicações neurológicas ocorreram preferencialmente em crianças saudáveis, enquanto as complicações infeciosas, nomeadamente as IBI foram mais frequentes nos doentes medicados previamente com ibuprofeno e/ou corticoide (Fig. 3). 


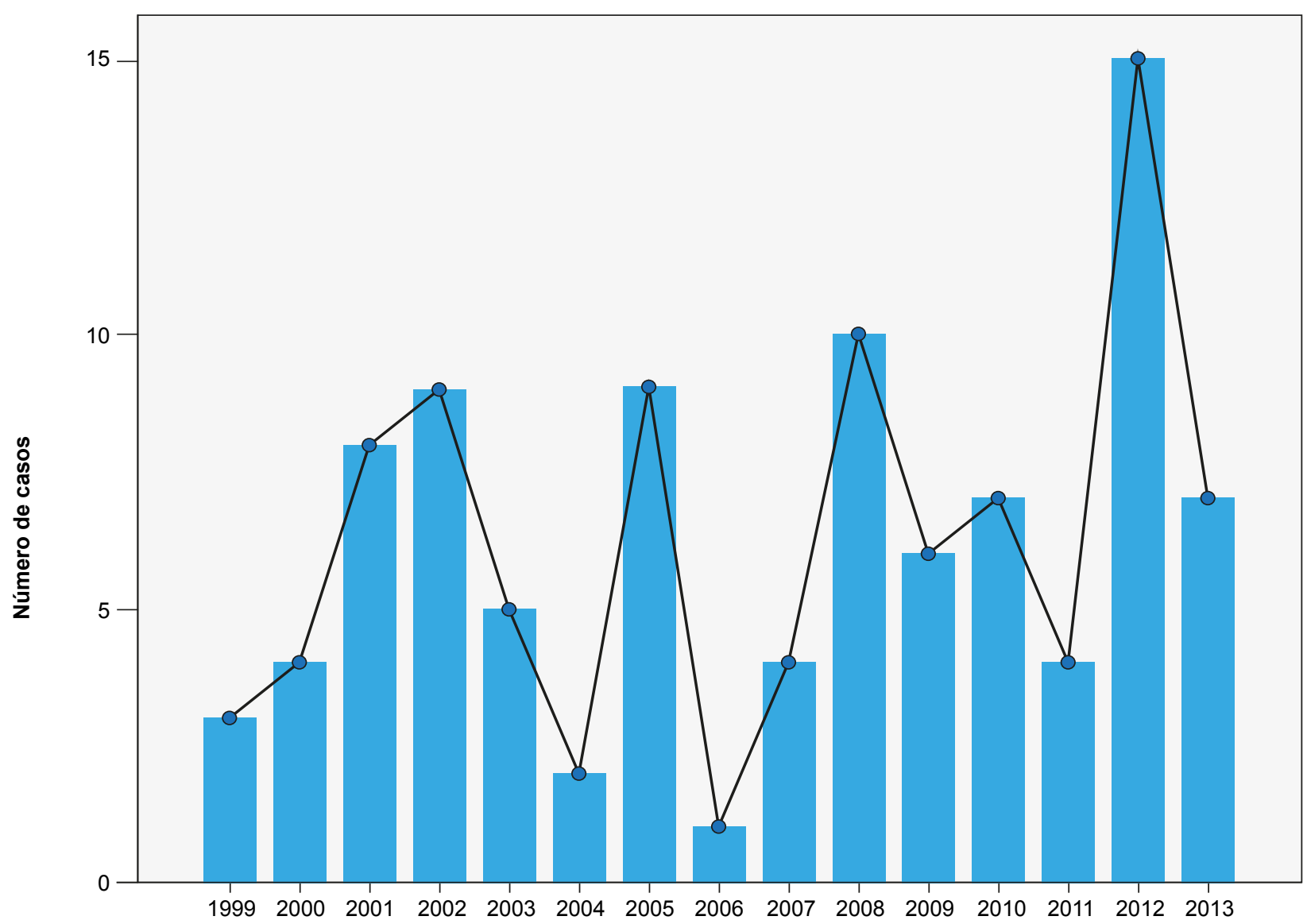

Ano de admissão

Figura 2 - Distribuição do número de casos por ano

\section{DISCUSSÃO}

A varicela é responsável por um número significativo de complicações com necessidade de internamento e afeta, não só grupos de risco, mas predominantemente crianças saudáveis. ${ }^{13-17} \mathrm{~A}$ incidência de hospitalização na Europa varia de 1,3 a 4,5/100 000 casos de varicela, sendo a taxa anual de mortalidade de $0,05 / 100000$ casos. ${ }^{5}$ Tal como era esperado, no nosso estudo o grupo de crianças em idade pré-escolar foi o mais afetado, ${ }^{13-21}$ uma vez que é nesta faixa etária que a varicela é mais frequente.
Em concordância com outros estudos, a sobreinfeção bacteriana da pele/tecidos moles foi a complicação mais frequente. 14,15,17,18,22-25,27 Tal como esperado, esta complicação predominou no grupo de crianças mais novas, enquanto as complicações imunológicas, nomeadamente as neurológicas ocorreram em crianças mais velhas ${ }^{13,17,21,22,28-30} \mathrm{e}$ mais tardiamente no decurso da doença. ${ }^{17,18,22}$ Os agentes mais comuns identificados nas complicações infeciosas foram o Staphylococcus aureus e o Streptococcus pyogenes, o que também está de acordo com o descrito na

Tabela 2 - Relação entre variáveis clínico-epidemiológicas e tipo de complicação

\begin{tabular}{|c|c|c|c|c|}
\hline Variáveis & $\begin{array}{c}\text { Complicações } \\
\text { infeciosas } \\
n=66\end{array}$ & $\begin{array}{c}\text { Complicações } \\
\text { imunológicas } \\
n=14\end{array}$ & $\begin{array}{l}\text { Total } \\
\mathrm{n}=94\end{array}$ & $p$ \\
\hline Sexo feminino $(\%)$ & 45,5 & 78,6 & 51,2 & 0,02 \\
\hline $\begin{array}{l}\text { Idade admissão em meses } \\
\text { (mediana) }\end{array}$ & $\begin{array}{c}30 \\
(\text { IQR: } 15-55)\end{array}$ & $\begin{array}{c}64 \\
(\text { IQR: } 48-95)\end{array}$ & $\begin{array}{c}38 \\
(\text { IQR: } 18-65)\end{array}$ & 0,001 \\
\hline $\begin{array}{l}\text { Tempo varicela-complicação em dias } \\
\text { (mediana) }\end{array}$ & $\begin{array}{l}\quad 4,0 \\
(\text { IQR: } 3,0-5,0)\end{array}$ & $\begin{array}{c}8,0 \\
\text { (IQR: } 4,0-12,5)\end{array}$ & $\begin{array}{l}\quad 4,0 \\
\text { (IQR: } 2,0-6,0)\end{array}$ & 0,001 \\
\hline $\begin{array}{l}\text { Tempo internamento em dias } \\
\text { (mediana) }\end{array}$ & $\begin{array}{c}5,0 \\
\text { (IQR: } 3,0-8,3)\end{array}$ & $\begin{array}{l}5,0 \\
\text { (IQR: } 2,8-7,0)\end{array}$ & $\begin{array}{c}5,0 \\
\text { (IQR: } 3,0-7,0)\end{array}$ & NS \\
\hline
\end{tabular}

NS: Não significativo; $p$ : Nível de significância; IQR: Interquartil range. Considerou-se uma probabilidade de erro de tipo I ( $\left.{ }^{(}\right)$de 0,05 em todas as análises inferencias. 


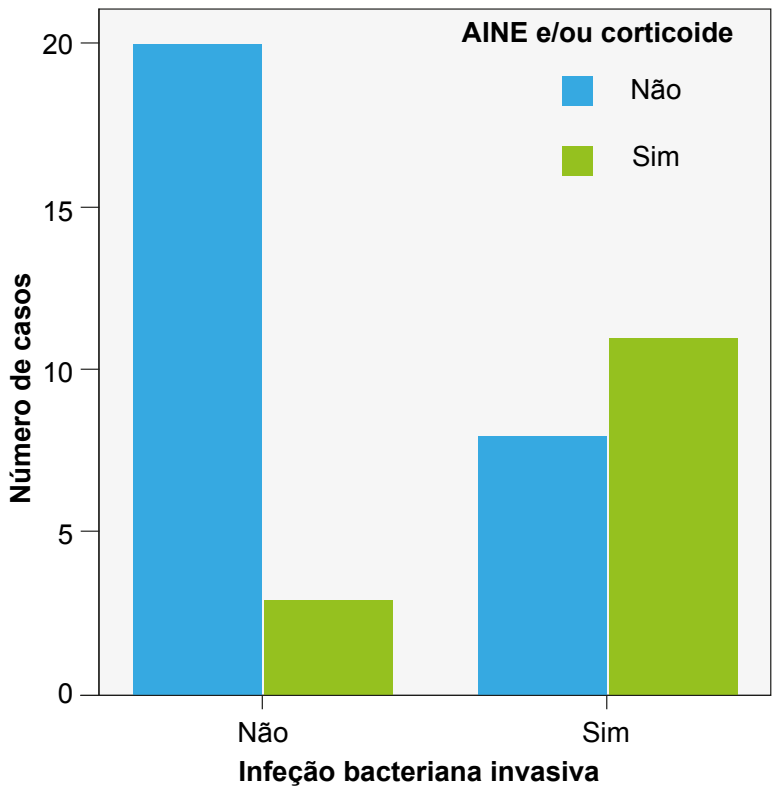

Figura 3 - Frequência de infeção bacteriana invasiva nos doentes sob terapêutica com AINE e/ou corticoide; $p=0,003$

literatura. ${ }^{11}$ As complicações respiratórias foram o segundo grupo mais frequente neste estudo, o que já foi descrito noutro estudo realizado no nosso país. ${ }^{17}$ No entanto, as complicações neurológicas são geralmente consideradas mais frequentes do que as respiratórias..$^{15,24}$ Tal pode ser devido ao facto de no nosso estudo terem sido incluídos nas complicações respiratórias os casos de infeção das vias aéreas superiores e também os casos de broncospasmo de provável etiologia vírica.

$\mathrm{Na}$ literatura têm surgido estudos que demostram um aumento do risco de complicações cutâneas graves associado ao uso de anti-inflamatórios não esteróides (AINEs), como o ibuprofeno, em crianças com varicela. Pensa-se que a exposição a AINEs diminua as defesas contra a infeção através do comprometimento da função dos neutrófilos. ${ }^{31}$ Neste estudo, verificou-se associação entre as complicações infeciosas, nomeadamente as IBI e a terapêutica prévia com ibuprofeno, o que corrobora esta hipótese. No entanto não foi identificado nenhum caso de fasceíte necrotizante. Os autores enfatizam a contra-indicação da prescrição do ibuprofeno e corticoide sistémico na varicela.

Em Portugal, o único medicamento disponível em suspensão oral (xarope) para o tratamento da varicela e que está aprovado para uso pediátrico é o aciclovir. Esta terapêutica não é recomendada universalmente pela Academia Americana de Pediatria para o tratamento de varicela não complicada em crianças saudáveis, mas deve ser considerada em adolescentes com idade superior a 13 anos, em crianças com idade superior a 12 meses e doença cutânea ou pulmonar crónica; em crianças sob terapêutica com corticosteróides e/ou salicilatos e nos segundos casos intrafamiliares. ${ }^{6}$ De acordo com a literatura, a utilização de aciclovir associa-se a uma redução do tempo de doença e do número de lesões cutâneas, especialmente quando prescrito nas primeiras 24 horas de doença. ${ }^{32,33} \mathrm{~A}$ inexistência de uma relação estatisticamente significativa no nosso estudo entre a administração de aciclovir e a gravidade e tipo de complicação pode ter sido influenciada pela dimensão da amostra. Além disso, a ausência de grupo controle não permite inferir conclusões adequadas sobre o uso de aciclovir e a redução das lesões e do tempo de internamento.

Nos Estados Unidos da América, a vacina contra a varicela foi introduzida em 1995, sendo recomendada a nível universal. Trata-se de uma vacina constituída por VVZ vivo atenuado (estirpe Oka), sendo segura no imunocompetente. ${ }^{9}$ Desde a implementação da vacina, tem-se assistido a uma redução da incidência e complicações da varicela. ${ }^{34,35}$ Uma análise dos custos relacionados com a epidemia anual por varicela mostrou que os programas de imunização universal direcionados para crianças saudáveis e adultos susceptíveis têm uma boa relação custo-eficácia e são seguros. ${ }^{11}$ No entanto, a OMS e o CDC enfatizam a necessidade de se assegurar uma cobertura vacinal superior a $85-90 \%$ nas populações onde é vacina é introduzida, para evitar o risco de desvio do pico de incidência, com aumento da população de adolescentes e adultos susceptíveis, o que levaria a um aumento da morbilidade global. Outra possível consequência é o aumento da incidência do herpes zoster. ${ }^{9}$ Atualmente, são já vários os países europeus que recomendam a vacinação universal contra a infeção por VVZ, tal como a Alemanha, Espanha, Itália, Holanda e Suiça. ${ }^{9}$ Nestes países, a implementação universal da vacina demonstrou ser uma estratégia eficaz na redução do número de casos, internamentos, consultas médicas e mortes. ${ }^{5} \mathrm{Em}$ Portugal a vacina foi introduzida em 2004, sendo recomendada apenas a adolescentes e grupos de risco.

Em janeiro de 2006 foi iniciado um estudo prospetivo da responsabilidade da Sociedade Portuguesa de Pediatria e do Instituto Nacional de Saúde Dr. Ricardo Jorge, baseado na notificação pela rede UVP-SPP dos casos de crianças e adolescentes internados em serviços de Pediatria com varicela ou herpes zoster. Entre 2006 e 2007, foram analisados 154 doentes (148 casos de varicela e seis casos de herpes zoster), sendo $60,0 \%$ do sexo masculino e apresentando $60,4 \%$ idade inferior a dois anos. Neste estudo as complicações mais frequentes foram a sobreinfeção bacteriana da pele e tecidos moles $(54,0 \%)$, seguindo-se as complicações neurológicas $(19,0 \%)$ e as complicações respiratórias $(11,0 \%)$. No entanto, as notificações foram reduzidas e predominantemente na zona sul do país (116 casos), o que impossibilita conclusões adequadas. ${ }^{10}$

\section{Limitações do estudo}

Este estudo apresentou algumas limitações. Uma delas prende-se com a ausência de seguimento da totalidade das crianças após a alta hospitalar, o que não permite estabelecer o número real de sequelas. Além disso, tendo em conta que as informações utilizadas são baseadas nos processos clínicos dos doentes e dependem do preenchimento dos profissionais de saúde, nalguns casos não foi possível 
averiguar alguns dados demográficos, clínicos e analíticos que poderiam ter influência na predição de complicações. Uma vez que o estudo reúne casos avaliados e registados por vários médicos num período de 14 anos, não foi possível obter homogeneidade no registo dos dados, o que pode ter condicionado algum erro de interpretação. Também não foi possível comparar os casos complicados com os não complicados nem averiguar o número real de casos de varicela na área de influência do Centro Hospitalar de Vila Nova de Gaia/Espinho.

\section{CONCLUSÃO}

As complicações da infeção pelo VVZ ocorreram preferencialmente em idade pré-escolar e doentes previamente saudáveis. As complicações infeciosas, nomeadamente as dermatológicas e respiratórias, foram as mais frequentes, tendo sido detetada associação com a terapêutica prévia com ibuprofeno e/ou corticoide, não devendo estas terapêuticas ser prescritas na varicela. Estudos multicêntricos deverão ser planeados no sentido de determinar a incidência nacional das infeções complicadas por VVZ bem como o impacto social e económico da doença, com o intuito de otimizar e ajustar as estratégias vacinais à nossa realidade.

\section{REFERÊNCIAS}

1. Bonhoeffer J, Baer G, Muehleisen B, Aebi C, Nadal D, Schaad U, et al. Prospective surveillance of hospitalisations associated with varicellazoster virus infections in children and adolescents. Eur J. 2005;164:36670.

2. Papaloukas O, Giannouli G, Papaevangelou V. Successes and challenges in varicella vaccine. Ther Adv Vaccines. 2014;2:39-55.

3. American Academy of Pediatrics, Committee on Infectious Diseases. Prevention of varicella: recommendations for use of varicella vaccines in children, including a recommendation for a routine 2-dose Varicella immunization schedule. Pediatrics. 2007;120:221-9.

4. Heininger U, Seward JF. Varicella. Lancet. 2006;368:1365-76.

5. Bonanni P, Breuer J, Gershon A, Gershon M, Hryniewicz W, Papaevangelou V, et al. Varicella vaccination in Europe - taking the practical approach. BMC Med. 2009;7:26.

6. Myers MG, Seward JF, LaRussa PS. Varicella-Zoster virus. In: Behrman RE, Kliegman RM, Jenson HB, Stanton BF, editors. Nelson Textbook of Pediatrics. $18^{\text {th }}$ ed. Philadelphia: Saunders Elsevier; 2007. p. 1366-72.

7. Médicos-Sentinela. O que se fez em 2009 (Relatório de Actividades Médicos-Sentinela 23). Departamento de Epidemiologia. Lisboa: Instituto Nacional de Saúde Dr. Ricardo Jorge; 2011.

8. Rodrigues I, Barreiro P. Avaliação do programa Nacional de Vacinação - $2^{\circ}$ Inquérito Serológico Nacional Portugal Continental 2001-2002. Lisboa: DGS; 2006. p. 113-22.

9. Sociedade de Infecciologia Pediátrica/Sociedade Portuguesa de Pediatria. Recomendações para a vacinação contra a varicela. Acta Pediatr Port. 2009;40:185-8.

10. Leça A, Branco MJ, Brito MJ, Gouveia C, Neves JF, Nunes B. Varicela ou herpes Zoster em crianças internadas. Sociedade Portuguesa de Pediatria [Consultado 2014 jan 25]. Disponível em: http://www.spp.pt.

11. Arvin AM. Varicella-Zoster virus. In: Long S, Pickering L, Prober C, editors. Principles and practice of pediatric infectious diseases. $3^{\text {rd }}$ edition. Edinburgh: Churchil Livingstone; 2008. p.1021-1029.

12. Llop FA. Complicaciones de la varicela en el niño inmunocompetente. An Pediatr. 2003;59:S18-26.

13. Galil K, Brown C, Lin F, Seward J. Hospitalizations for varicella in the United States, 1998 to 1999. Pediat Infect Dis J. 2002;21:931-4.

14. Jackson MA, Burry FV, Olson LI. Complications of varicella requiring hospitalization in previously healthy children. Pediatr Infect Dis J. 1992;11:441-5

15. Peterson CL, Mascola L, Chao SM. Children hospitalized for varicella: a

\section{OBSERVAÇÕES}

Apresentado sobre a forma de poster com apresentação em sala no $14^{\circ}$ Congresso Nacional de Pediatria, no Porto, de 3 a 5 de outubro de 2013

\section{PROTECÇÃO DE PESSOAS E ANIMAIS}

Os autores declaram que $O$ projeto de investigação deste estudo foi previamente aprovado pela Comissão de Ética da instituição em que a investigação foi realizada, de acordo com a Declaração de Helsínquia da Associação Médica Mundial e do International Committee of Medical Journal Editors (ICMJE).

\section{CONFIDENCIALIDADE DOS DADOS}

Os autores declaram ter seguido os protocolos do seu centro de trabalho acerca da publicação dos dados de doentes.

\section{CONFLITOS DE INTERESSE}

Os autores declaram não ter nenhum conflito de interesses relativamente ao presente artigo.

\section{FONTES DE FINANCIAMENTO}

Não existiram fontes externas de financiamento para a realização deste artigo.

prevaccine review. J Pediatr. 1996;129:529-36.

16. Bonhoeffer J, Baer G, Muehleisen B, Aebi C, Nadal D, Schaad UB, et al. Prospective surveillance of hospitalisations associated with varicellazoster virus infections in children and adolescents. Eur $\mathrm{J}$ Pediatr. 2005;164:366-70.

17. Carvalho I, Caldeira T, Santos F. Hospitalizações por complicações da varicela. Acta Pediatr Port. 2005;36:229-32.

18. Guess HA, Broughton DD, Melton LJ, Kurland LT. Population-based studies of varicella complications. Pediatrics. 1986;78:S723-7.

19. Yawn BP, Yawn RA, Lydick E. Community impact of childhood varicella infections. J Pediatr. 1997;130:759-65.

20. Fairley CK, Miller E. Varicella-zoster virus epidemiology: a changing scene? J Infect Dis. 1996;74:314-9.

21. Ziebold C, von Kries R, Lang R, Weigl J, Schmitt HJ. Severe complications of varicella in previously healthy children in Germany: a 1-year survey. Pediatrics. 2001;108:E79.

22. Preblud SR. Varicella: complications and costs. Pediatrics. 1986;78:72835.

23. Fleisher G, Henry W, McSorley M, Arbeter A, Plotkin S. Lifethreatening complications of varicella. Am J Dis Child. 1981;135:896-9.

24. Fernandes S, Rocha G, Januário L. Hospitalizações por varicela no Hospital Pediátrico de Coimbra (2000-2007). Acta Pediatr Port. 2010;41:205-8.

25. Maharshak N, Somekh E. Hospitalization for varicella in central Israel. Acta Paediatr. 1999;88:1279-83.

26. Riaza Gomez M, de la Torre Espi M, Mencia Bartolome S, Molina Cabañero JC, Tamariz-Martel Moreno A, et al. Complications of varicella in children. An Esp Pediatr. 1999;50:259-62.

27. Choo PW, Donahue JG, Manson JE, Platt R. The epidemiology of varicella and its complications. J Infect Dis. 1995;172:706-12.

28. Mandelcwajg A, Quinet B, Castello B, Parez N, Grimprel E. Causes of hospitalization of patients with ongoing varicella in a French children hospital: evolution between 1990 and 2001. Arch Pediatr. 2006;13:42935.

29. Koturoglu G, Kurugol Z, Cetin N, Hizarcioglu M, Vardar F, Helvaci M, et al. Complications of varicella in healthy children in Izmir, Turkey. Pediatr Int. 2005;47:296-9.

30. Marcheto S. Epidemiology of hospital admissions for chickenpox in children: an Italian multicentre study in the pre-vaccine era. Acta Paediatr. 2007;96:1490-3. 
31. Mikaeloff $Y$, Kezouh A, Suissa S. Nonsteroidal anti-inflammmatory drug use and the risk of severe skin and soft tissue complications in patients with varicella or zoster disease. BJCP. 2007;65:203-9.

32. Klassen TP, Belseck EM, Wiebe N, Hartling L. Acyclovir for treating varicella in otherwise healthy children and adolescents. Cochrane Database Syst Rev. 2005;4:CD 002980.

33. Margo KL, Shaughnessy AF. Antiviral drugs in healthy children. Am Fam
Physician. 1998; 57:1073-7.

34. Seward JF, Watson BM, Peterson CL, Mascola L, Pelosi JW, Zhang $\mathrm{JX}$, et al. Varicella disease after introduction of varicella vaccine in the United States, 1995-2000. JAMA. 2002;287:606-11.

35. Nguyen $\mathrm{HQ}$, Jumaan $A O$, Seward JF. Decline in mortality due to varicella after implementation of varicella vaccination in the United States. N Engl J Med. 2005;352:450-8. 


\section{Estudo Clínico-Epidemiológico da Infeção Complicada por Vírus Varicela-Zoster na Idade Pediátrica}

Acta Med Port 2015:28:741-748

Publicado pela Acta Médica Portuguesa, a Revista Científica da Ordem dos Médicos

Av. Almirante Gago Coutinho, 151

1749-084 Lisboa, Portugal.

Tel: +351218428215

E-mail: submissao@actamedicaportuguesa.com

www.actamedicaportuguesa.com

ISSN:0870-399X | e-ISSN: 1646-0758

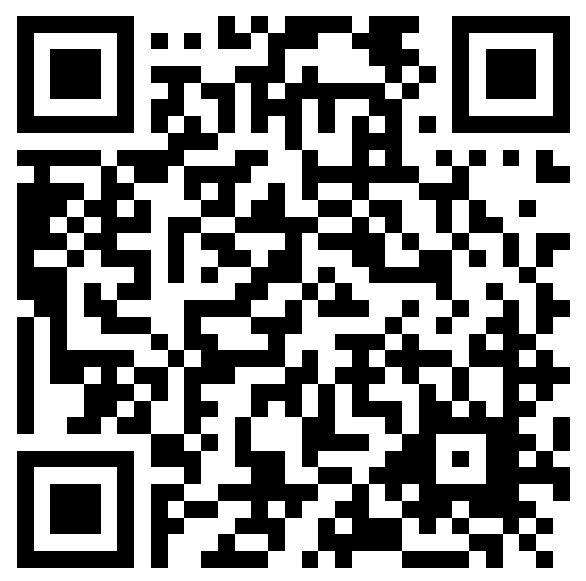

